\title{
The neurobehavioural rating scale-revised: sensitivity and validity in closed head injury assessment
}

S R McCauley, H S Levin, M Vanier, J-M Mazaux, C Boake, P R Goldfader, D Rockers, M Butters, D A Kareken, J Lambert, G L Clifton

Department of Physical Medicine and Rehabilitation, Baylor College of Medicine, 6560 Fannin, Ste 1144, Houston, TX 77030, USA

S R McCauley

H S Levin

Department of

Neurosurgery

H S Levin

Department of Psychiatry

H S Levin

Ecole de Réadaptation, Université de Montréal, Montréal, Canada

M Vanier

Centre Hospitalier Universitaire de Bordeaux, Bordeaux, France

J-M Mazaux

Department of Physical Medicine and Rehabilitation, The University of Texas Health Science Center, Houston, USA

C Boake

Department of

Neurosurgery

G L Clifton

Departments of Neurology and Neurosurgery, St Louis University School of Medicine, St Louis, USA

P R Goldfader

Department of Neurological Surgery, University of California, Davis, Sacramento, USA D Rockers

Department of Neurology, Indiana University School of Medicine,

Indianapolis, USA

D A Kareken
Abstract

Objectives-To investigate the factor structure and psychometric properties of the neurobehavioural rating scale-revised (NRS-R) and to determine its usefulness in clinical trials.

Methods-A consecutive series of patients sustaining severe closed head injury were evacuated to one of 11 large regional North American trauma centres and entered into a randomised, phase III, multicentre clinical trial investigating the therapeutic use of moderate hypothermia. Acute care personnel were blinded to outcome and outcome personnel were blinded to treatment condition. The Glasgow outcome scale (GOS) was the primary outcome measure. Secondary outcome measures included the disability rating scale (DRS) and the NRS-R.

Results-Exploratory factor analysis of NRS-R data collected at 6 months after injury $(n=210)$ resulted in a five factor model including: (1) executive/cognition, (2) positive symptoms, (3) negative symptoms, (4) mood/affect, and (5) oral/motor. These factors showed acceptable internal consistency ( 0.62 to 0.88$)$, low to moderate interfactor correlations $(0.19$ to 0.61$)$, and discriminated well between GOS defined groups. Factor validity was demonstrated by significant correlations with specific neuropsychological domains. Significant change was measured from 3 to 6 months after injury for the total score (sum of all 29 item ratings) and all factor scores except mood/affect and positive symptoms. The total score and all factor scores correlated significantly with concurrent GOS and DRS scores.

Conclusions-The NRS-R is well suited as a secondary outcome measure for clinical trials as its completion rate exceeds that of neuropsychological assessment and it provides important neurobehavioural information complementary to that provided by global outcome and neuropsychological measures.

(F Neurol Neurosurg Psychiatry 2001;71:643-651)

Keywords: outcome measures; head injury; randomised clinical trials; neurobehavioural sequelae

The neurobehavioural rating scale (NRS) of Levin $e t a l^{1}$ is a 27 item, multidimensional clinician based assessment instrument designed to measure neurobehavioural disturbances. Based on the brief psychiatric rating scale, ${ }^{2}$ the NRS included items which would be more specific to patients with neuropsychiatric symptomatology resulting from closed head injury. Levin et $a l^{1}$ reported a four factor solution to the NRS using principal components analysis in a sample of 101 patients with closed head injury (covering a wide range of injury severity), including: cognition/energy, metacognition, somatic/anxiety, and a language factor. Significant changes in factor scores were reported from the initial assessment at 3 months after injury to follow up testing at 6 months after closed head injury for cognition/ energy, metacognition, and language. The NRS has been shown to be a reliable and valid $^{13-5}$ instrument for quantifying behavioural disturbances and gross cognitive impairments in those with neuropsychiatric syndromes, including head injury, ${ }^{3-10}$ dementia, ${ }^{411-16}$ and HIV disease. ${ }^{5}$

To enhance the reliability and content validity of the NRS, Levin et $a l^{17}$ developed the NRS-Revised (NRS-R). Changes to the NRS-R include the addition of two items ("difficulties in mental flexibility" and "irritability"), consolidation of two previous items into a single item ("tension" and "anxiety" merged together as "anxiety"), and separation of other items ("inattention" divided into "reduced alertness" and "attention"). To improve scoring reliability, the anchor points were more clearly defined and the Likert scale was condensed from a 7 point to a 4 point scale (absent, mild, moderate, and severe). The ratings for each item are defined on the basis of the potential impact of the behaviour on social and occupational independence. The NRS-R is administered through a brief structured interview (typically requiring 15-20 minutes to complete) which includes a test of orientation and memory for recent events, questions regarding emotional state, postconcussional symptoms, focused attention, and concentration (performing serial sevens), explanation of proverbs, tasks of planning and mental flexibility, and delayed recall of three objects presented at the beginning of a session. Observations are also made regarding the patient's fatigability, visible signs of anxiety, disinhibition, agitation, hostility, difficulties in expressive and receptive communication, and disturbance of mood. About one third of the item 
ratings are based solely on examiner observation which are graded according to a behaviourally anchored four point rating scale. The balance of the items are rated according to the patient's performance on brief tasks and quality of answers to interview questions.

In a French multicentre study in which data were collected at rehabilitation hospitals on 286 patients with closed head injury, Vanier et $a l^{18}$ assessed the interrater reliability of the NRS-R through videotaped interviews in a randomly selected subgroup of 70 patients who had sustained closed head injury ranging from mild to severe according to the Glasgow coma scale (GCS) score of Teasdale and Jennett. ${ }^{19}$ These videotapes of the NRS-R structured interview and mental status examination were rated based on a single viewing by two independent examiners at other centres involved in the project. Vanier et al reported that no item had a substantially low percentage of interexaminer agreement or $\kappa$ value. The mean percentages of agreement among all 29 items was $73.6 \%$. The mean $\kappa$ statistic for three independent observers was acceptable at 0.43 with a range in value across the NRS-R items from 0.22 ("difficulty in planning") to 0.77 ("memory difficulties").

Factor analysis of the NRS-R data for the total sample of 286 patients with closed head injury in the French multicentre study ${ }^{18}$ disclosed five correlated factors (using oblique rotation) which explained $42.2 \%$ of the total variance. Factor I (intentional behaviour) consisted of items pertaining to intentional or goal oriented behaviour (for example, difficulties in self appraisal, initiative, and motivation, mental flexibility, and planning, blunted affect, conceptual disorganisation, disorientation, and memory problems). Factor II (lowered emotional state) included depressive mood, anxiety, and emotional withdrawal, factor III (survival oriented behaviour/heightened emotional state) consisted of items such as irritability, disinhibition, hostility, and hyperactivityagitation, factor IV (arousal state) had items such as reduced alertness, inattention, and mental fatiguability, and factor $\mathrm{V}$ (language) consisted mainly of expressive and comprehension language skills. Although the study by Vanier et al provided empirical support for the interrater reliability and validity of the NRS-R while identifying five factors, the cross sectional design precluded analysis of the sensitivity of the NRS-R to changes over time. In the course of a multicentre clinical trial which utilised the NRS-R, we investigated the factor structure and scale properties of this instrument in a sample of patients with severe head injury who were studied longitudinally.

\section{Mepartment de}

Médecine Sociale et

Preventive, Université

de Montréal, Montréal,

Canada

J Lambert

Correspondence to: Dr H S Levin

hlevin@bcm.tmc.edu

Received 15 May 2000 and in revised form

30 May 2001

Accepted 27 June 2001 hypothermia to treat severe closed head injury. Inclusion criteria consisted of an abnormal CT obtained within 24 hours of injury, and a postresuscitation GCS motor score of 1 to 5 (total GCS $\leqslant 8$ ). Exclusion criteria included evidence of hypotension (systolic $\mathrm{BP}<90 \mathrm{~mm} \mathrm{Hg}$ for $\geqslant 30$ minutes after resuscitation), hypoxia (saturation< $<4 \%$ ) for 30 minutes after resuscitation, estimated abbreviated injury severity ${ }^{20}$ score $\geqslant 4$ for any organ system, GCS of 3 with unreactive pupils, or inability to randomise within 6 hours of injury. Consent to randomise was obtained from appropriate family members or relevant others. Outcome personnel were blinded to the patient's treatment condition, and the acute care personnel were blinded to the patient's outcome at the assessment 3 months after closed head injury and the 6 month evaluation which was the primary end point.

\section{COMPLETION RATE}

Of the 392 patients enrolled, 105 (26.8\%) died before the 6 month end point. A total of 77 patients (who formed the non-study group) were excluded from further analyses for the following reasons. Thirty patients $(7.7 \%)$ were conscious but too impaired to begin or complete the NRS-R, and $18(4.6 \%)$ were in a persistent vegetative state. Examiners went to great lengths to obtain outcome information including travel to foreign countries, with only seven patients $(1.2 \%)$ lost to follow up at 6 months after injury. Three patients $(0.8 \%)$ were excluded who were assessed outside their 6 month testing window, and one $(0.3 \%)$ was excluded who fell outside the 15 to 65 year age range. Eleven patients $(2.8 \%)$ refused testing either in the hospital or rehabilitation facility where they had been transferred, in their home, or at other locations. Primary outcome data for these patients were obtained through interview with a reliable informant by telephone. The NRS-R was translated into Spanish resulting in only four $(1.0 \%)$ patients being excluded for speaking a language other than English or Spanish. Three patients were not tested on the NRS-R for reasons unrelated to the patient. Of the total group of survivors, completion rates for other outcome measures at 6 months were $97.6 \%$ for the Glasgow outcome scale ${ }^{2122}$ (GOS), $96.1 \%$ for the disability rating scale, ${ }^{23}$ $74.9 \%$ for the NRS-R, $72.1 \%$ for the neuropsychological test with the highest completion rate (controlled oral word association ${ }^{24}$ ), and $63.8 \%$ for the two neuropsychological tests with the lowest rate of completion (trail making test $b^{25}$ and grooved pegboard ${ }^{26-28}$ ). Of the patients in the study group, $42.5 \%$ were unable to complete some or all of the brief, 2 hour neuropsychological battery administered in this study. Table 1 summarises the demographic and injury severity characteristics of the survivors in the study and non-study groups.

Analyses by $\chi^{2}$ indicated that there was not a significant difference between the survivors in the study and non-study groups for $\operatorname{sex}\left(\chi^{2}(1\right.$, $\mathrm{n}=286)=0.27, \mathrm{p}=0.6)$, or postresuscitation pupil reactivity $\left(\chi^{2}(2, \mathrm{n}=283)=3.4, \mathrm{p}=0.18\right)$. A 
Table 1 Demographics and injury severity characteristics of the survivors in the study and non-study groups

\begin{tabular}{lllll}
\hline & Study group & \multicolumn{2}{l}{ Non-study group $^{*}$} \\
\hline $\begin{array}{llll}\text { Number of patients } \\
\text { Sex: }\end{array}$ & 210 & & 77 & \\
$\quad$ Male & 151 & $71.9 \%$ & 57 & $75.0 \%$ \\
$\quad$ Female & 59 & $28.1 \%$ & 19 & $25.0 \%$ \\
Mean age (y) at injury & 29.5 & $(11.0)$ & 35.4 & $(13.4)$ \\
Mean years of education & 11.8 & $(2.3)$ & 12.1 & $(2.4)$ \\
Ethnicity: & 175 & $83.3 \%$ & 48 & $64.9 \%$ \\
$\quad$ White & 15 & $7.1 \%$ & 12 & $16.2 \%$ \\
$\quad$ African-American & 14 & $6.7 \%$ & 12 & $16.2 \%$ \\
$\quad$ Hispanic & 6 & $2.9 \%$ & 5 & $2.7 \%$ \\
$\quad$ Asian/other & & & & \\
Primary language: & 201 & $95.7 \%$ & 63 & $81.8 \%$ \\
$\quad$ English & 9 & $4.3 \%$ & 10 & $12.9 \%$ \\
$\quad$ Spanish & 0 & $0.0 \%$ & 4 & $5.3 \%$ \\
$\quad$ Other & 6.0 & $(1.2)$ & 5.4 & $(1.3)$ \\
Glasgow coma scale (postresuscitation) & & & & $58.4 \%$ \\
Pupil response (post-resuscitation): & 146 & $70.5 \%$ & 45 & $14.3 \%$ \\
$\quad$ Normal (bilaterally) & 24 & $11.6 \%$ & 11 & $26.0 \%$ \\
$\quad \begin{array}{l}\text { Abnormal (unilaterally) } \\
\text { Abnormal (bilaterally) }\end{array}$ & 37 & $17.8 \%$ & 20 & \\
\hline
\end{tabular}

The numbers in parentheses are SD.

*The non-study group includes patients who were too impaired to begin or complete testing, refused testing, etc. an NINDS sponsored conference on outcome measures in clinical trials, ${ }^{34}$ a brief battery of neuropsychological tests was completed at the 6 month assessment, including tests of verbal and visual memory (Buschke verbal selective reminding test $^{35} 36$ and the immediate and delayed recall trials of the Rey-Osterrieth complex figure $\left.{ }^{37}{ }^{38}\right)$, speed dependent visuomotor tracking (trail making test $\mathrm{B}^{24}$ and the symboldigit modalities test ${ }^{39}{ }^{40}$ ), manual dexterity (grooved pegboard ${ }^{26}{ }^{27}$ ), and speeded language production (controlled oral word association test $^{24}$ ). Patients were financially compensated for their participation in this study.

In the NABIS: $\mathrm{H}$ trial, psychometricians and a supervising psychologist from each centre attended a prestudy workshop during which the NRS-R, in addition to other primary outcome and neuropsychological measures, was presented and individual training was conducted to ensure consistency in test administration across centres. The supervising psychologist at each site reviewed the completed test materials for accuracy before forwarding them to the primary centre (Houston). The study's outcome monitor (SRM) additionally audited $100 \%$ of all protocols before entering them into a computer database. To guard against examiner drift, the outcome monitor was required to make regular site visits and observe the testing of study patients. $M=5.37$ (SD1.031)) relative to the group ( $M=6.04$ (SD 1.023)). The two groups differed significantly for the GOS category score at 6 months $\left(\chi^{2}(3, \mathrm{n}=280)=86.5\right.$, $\mathrm{p}=0.001)$, in that the non-study group was significantly more impaired with respect to the study group, due primarily to the number of patients with severe disability $(n=37)$ or persistent vegetative state $(n=18)$ ratings. Comparison of the mean 6 month disability score (DRS) found similar results ( $t$ $(274)=14.3, \mathrm{p}<0.0001)$ with the mean study group DRS of 3.93 (SD 3.42), and the mean non-study group DRS of 14.36 (SD 8.66). These findings are consistent with previous studies which have reported higher mortality and morbidity rates in older patients with closed head injury. ${ }^{28-33}$ No significant difference was found for years of education $(t(268)=0.81$, $\mathrm{p}=0.41)$. For comparison with other outcome studies, $31.9 \%$ of the study group was rated as having "good recovery" on the GOS, whereas $40.0 \%$ had "moderate disability," and $28.1 \%$ had a "severe disability" at 6 months after injury.

\section{PROCEDURE}

The NRS-R was administered at 3 months (76-104 day target window) and at 6 months (150-210 day target window) after injury. For this sample, the mean number of days after injury was 94.1 (SD 10.2) for the 3 month evaluation and 189.6 (SD 19.2) for the 6 month evaluation. A system of reliability codes ensured that protocols with no modifications or only minor deviations from normal administration were used in the analyses.

In addition to the NRS-R, the GOS and the DRS were determined for each patient at 3 and 6 months. In accordance with guidelines from

\section{Results}

FACTOR ANALYSIS OF THE NEUROBEHAVIOURAL RATING SCALE: REVISED

Factor analysis of the NRS-R was performed using the maximum likelihood (ML) procedure with oblique rotation for the total sample $(n=210)$. The relation between sample size and number of variables was sufficient with more than five patients/variable. ${ }^{41}$ There were no missing data points. Review of the literature regarding previous factor analyses of the NRS suggested that the number of factors necessary to adequately characterise the major components ranged between four ${ }^{1}$ and six. ${ }^{11}$ Additionally, Vanier $e t a l^{18}$ reported a five factor solution in their sample for the French version of the NRS-R.

The current ML analysis yielded five factors for which scores were formed by summing the ratings of items with loadings $\geqslant 0.38$ on a given factor. This correlation criterion is in line with Steven $\mathrm{s}^{42}$ who suggests adjusting the minimum level of significance of factor loadings according to sample size rather than an arbitrary 0.3 or higher. The value at $\alpha=0.01$ for a significant two tailed correlation is $\geqslant 0.38$ in a sample of 210 patients. The five factor model accounted for $93 \%$ of the total variance.

As shown in table 2, factor I (executive/ cognition) comprised items which included difficulties in mental flexibility, difficulties in planning, difficulties in oral comprehension, inaccurate self appraisal, and memory difficulties. Factor II (positive symptoms: distortions or exaggerations of normal functions) was made up of items such as unusual thought content, suspiciousness, hyperactivity/ 
Table 2 Maximum likelihood with obliquely rotated factor structure $(n=210)$

\begin{tabular}{|c|c|c|c|c|c|c|}
\hline & $\begin{array}{l}\text { Executive / } \\
\text { cognition }\end{array}$ & $\begin{array}{l}\text { Positive } \\
\text { symptoms }\end{array}$ & $\begin{array}{l}\text { Negative } \\
\text { symptoms }\end{array}$ & Mood / affect & Oral / motor & \\
\hline Coefficient $\alpha$ & 0.88 & 0.75 & 0.62 & 0.72 & 0.75 & \\
\hline$\%$ Variance & 57.2 & 14.1 & 9.6 & 6.6 & 5.5 & Communalities \\
\hline \multicolumn{7}{|l|}{ NRS-R items } \\
\hline Difficulty in planning & 91 & 5 & -9 & 4 & -8 & 0.750 \\
\hline Difficulty in mental flexibility & 72 & 3 & 2 & 1 & -2 & 0.530 \\
\hline Memory difficulties & 69 & 8 & -13 & 14 & 7 & 0.601 \\
\hline Disorientation & 63 & 20 & 5 & -15 & 4 & 0.532 \\
\hline Decreased initiative or motivation & 61 & -10 & 34 & 12 & -11 & 0.633 \\
\hline Self appraisal difficulties & 61 & -1 & 10 & -4 & 16 & 0.499 \\
\hline Conceptual disorganisation & 55 & 14 & 5 & 6 & -5 & 0.405 \\
\hline Difficulties in oral comprehension & 40 & 23 & 2 & -6 & 20 & 0.379 \\
\hline Unusual thought content & 2 & 68 & 17 & -22 & 10 & 0.508 \\
\hline Hyperactivity/agitation & -5 & 63 & -1 & 6 & 1 & 0.399 \\
\hline Disinhibition & 9 & 61 & -1 & 3 & 0 & 0.424 \\
\hline Excitement & 20 & 47 & -18 & 0 & -10 & 0.274 \\
\hline Lability of mood & -4 & 46 & -17 & 46 & 13 & 0.503 \\
\hline Suspiciousness & -2 & 40 & 25 & 12 & -7 & 0.310 \\
\hline Emotional withdrawal & 1 & -11 & 61 & 5 & 4 & 0.405 \\
\hline Hostility & -16 & 40 & 59 & 0 & -5 & 0.517 \\
\hline Blunted affect & 27 & -13 & 55 & -20 & 7 & 0.433 \\
\hline Exaggerated somatic concern & -8 & 3 & 42 & 29 & -10 & 0.271 \\
\hline Depressive mood & 3 & -7 & -3 & 74 & 5 & 0.550 \\
\hline Anxiety & -4 & 8 & 7 & 62 & -7 & 0.401 \\
\hline Irritability & 0 & 21 & 31 & 42 & -6 & 0.455 \\
\hline Mental fatigability & 8 & -11 & 19 & 39 & 39 & 0.539 \\
\hline Difficulties in articulation & 1 & 5 & -7 & -5 & 87 & 0.712 \\
\hline Motor slowing & 34 & -14 & -1 & 3 & 48 & 0.513 \\
\hline Difficulties in oral expression & 15 & 5 & 2 & 1 & 47 & 0.334 \\
\hline Reduced alertness & 14 & -20 & 30 & 24 & 22 & 0.394 \\
\hline Attention & 21 & 30 & 18 & 19 & 17 & 0.493 \\
\hline Hallucinations & 9 & 21 & -10 & 6 & -8 & 0.065 \\
\hline Guilt & -20 & 4 & 8 & 9 & -6 & 0.040 \\
\hline
\end{tabular}

Factor loadings have been rounded and converted to integers. Loadings $\geqslant 38$ are significant.

agitation, and disinhibition. Factor III (negative symptoms: a diminishment or absence of functions normally present) was derived from items that reflected emotional withdrawal, blunted affect, and hostility. Factor IV (mood/ affect) included items measuring depressive mood, anxiety, irritability, mental fatigability, and lability of mood. Factor $\mathrm{V}$ (oral/motor) consisted of items rating difficulties in articulation, difficulties in oral expression, and motor slowing.

Three items loaded significantly on two factors. These multiple loading items included "mental fatiguability" (mood/affect and oral/ motor), "hostility" (positive symptoms and negative symptoms) and "lability of mood" (positive symptoms and mood/affect). The internal consistency (Cronbach's coefficient $\alpha$ ) of the factors was acceptable ranging from 0.62 (negative symptoms) to 0.88 (executive/ cognition). The interfactor correlations were minimal to moderate ranging from 0.19 (positive symptoms and oral/motor) to 0.61 (executive/cognition and oral/motor). Four items did not load significantly on any factor including "attention," "reduced alertness," "guilt," and "hallucinations." Although these items are not part of the five factor solution, the clinician may wish to retain these items in the patient's examination as they provide important information which may have clinical relevance for specific patients.

For descriptive purposes, the frequency distribution of the NRS-R ratings is presented in table 3. Deficits found in at least $50 \%$ of the patients were generally from the items on the executive/cognition factor, including difficulty in planning, mental flexibility, impaired self appraisal, and conceptual disorganisation. In addition, over $50 \%$ of the sample demonstrated evidence of some degree of depressive mood. The NRS-R total score (simple sum of the 29 item scores) is included in the following analyses to demonstrate the utility of the NRS-R as a single composite measure of neurobehavioural disturbance in addition to the factor scores.

RELATION OF DEMOGRAPHIC VARIABLES AND INJURY SEVERITY TO NRS-R SCORES

There were no significant effects of age, education, or sex or any interactions of these variables on the NRS-R total score or any of the five factor scores. The NRS-R total score and all five factor scores obtained at 6 months after injury were correlated with the admission (postresuscitation) GCS score. Modest but significant associations were found between the GCS score and the NRS-R total score $(r=-0.20, \quad \mathrm{p}=0.005), \quad$ executive/cognition $(r=-0.18, \mathrm{p}=0.01)$, positive symptoms ( $r=-$ $0.17, \mathrm{p}=0.01)$, and oral $/$ motor factor scores $(r=-0.24, \mathrm{p}=0.0008)$.

\section{RELATION OF GLOBAL OUTCOME SCALES TO}

NRS-R FACTOR SCORES

One way analysis of variance (ANOVA) for group differences (based on groups formed by GOS ratings at 6 months after injury) indicated significant differences for the NRS-R total score $(F(2,207)=116.5, \mathrm{p}<0.0001)$ and each of the five factor scores (all at $\mathrm{p}<0.0001$ ). Post hoc comparisons (using Tukey's procedure to control type I error) between these groups ( $1 v$ $2,1 v 3$, and $2 v 3$ ) indicated significant differences in the NRS-R total score for each of the three comparisons. In a similar fashion, one way ANOVAs were calculated within each of 
Table 3 Frequency distributions of the NRS-R items at 6 months postinjury

\begin{tabular}{|c|c|c|c|c|}
\hline & \multicolumn{4}{|c|}{ Rating (\% at each level) } \\
\hline & Absent & Mild & Moderate & Severe \\
\hline \multicolumn{5}{|l|}{ I Executive/cognition: } \\
\hline Difficulty in planning & 34.3 & 30.5 & 26.7 & 8.6 \\
\hline Difficulty in mental flexibility & 34.3 & 34.3 & 23.8 & 7.6 \\
\hline Memory difficulties & 29.5 & 33.3 & 28.1 & 9.0 \\
\hline Disorientation & 62.9 & 6.2 & 10.5 & 20.5 \\
\hline Decreased initiative or motivation & 53.8 & 25.7 & 15.2 & 5.2 \\
\hline Self appraisal difficulties & 36.7 & 32.4 & 19.0 & 11.9 \\
\hline Conceptual disorganisation & 22.4 & 48.1 & 26.7 & 2.9 \\
\hline Difficulties in oral comprehension & 69.5 & 28.1 & 1.9 & 0.5 \\
\hline \multicolumn{5}{|l|}{ II Positive symptoms: } \\
\hline Unusual thought content & 86.2 & 12.4 & 1.0 & 0.5 \\
\hline Disinhibition & 81.9 & 12.9 & 4.3 & 1.0 \\
\hline Hyperactivity/agitation & 87.1 & 11.4 & 1.0 & 0.5 \\
\hline Lability of mood & 74.3 & 21.9 & 3.3 & 0.5 \\
\hline Excitement & 82.9 & 12.9 & 3.8 & 0.5 \\
\hline Suspiciousness & 91.9 & 7.1 & 1.0 & 0.0 \\
\hline Hostility & 88.1 & 9.0 & 2.4 & 0.5 \\
\hline \multicolumn{5}{|l|}{ III Negative symptoms: } \\
\hline Emotional withdrawal & 70.5 & 25.7 & 3.3 & 0.5 \\
\hline Hostility & 88.1 & 9.0 & 2.4 & 0.5 \\
\hline Blunted affect & 70.5 & 22.4 & 6.2 & 1.0 \\
\hline Exaggerated somatic concern & 92.9 & 6.2 & 0.5 & 0.5 \\
\hline \multicolumn{5}{|l|}{ IV Mood/affect: } \\
\hline Depressive mood & 49.0 & 34.8 & 15.7 & 0.5 \\
\hline Anxiety & 53.3 & 36.7 & 10.0 & 0.0 \\
\hline Irritability & 52.9 & 37.1 & 8.1 & 1.9 \\
\hline Lability of mood & 74.3 & 21.9 & 3.3 & 0.5 \\
\hline Mental fatigability & 70.0 & 21.4 & 6.7 & 1.9 \\
\hline \multicolumn{5}{|l|}{ V Oral/motor: } \\
\hline Difficulties in articulation & 79.0 & 13.3 & 6.7 & 1.0 \\
\hline Motor slowing & 64.3 & 21.4 & 10.5 & 3.8 \\
\hline Difficulties in oral expression & 67.1 & 27.1 & 5.7 & 0.0 \\
\hline Mental fatigability & 70.0 & 21.4 & 6.7 & 1.9 \\
\hline \multicolumn{5}{|l|}{ Items not loading on any factor: } \\
\hline Attention & 53.8 & 31.4 & 12.9 & 1.9 \\
\hline Reduced alertness & 79.5 & 20.5 & 0.0 & 0.0 \\
\hline Guilt & 70.5 & 28.6 & 1.0 & 0.0 \\
\hline Hallucinations & 91.9 & 7.1 & 1.0 & 0.0 \\
\hline
\end{tabular}

the five factor scores for between group comparisons (fig 1). Significant differences were found for the three between group comparisons for the executive/cognition, $\mathrm{mood} / \mathrm{affect}$, and oral/motor factors such that more severe dysfunction or deficit was associated with greater levels of disability measured on the GOS. Similar results were found for the positive symptoms and negative symptoms factor scores except for the good recovery versus moderate disability comparisons.

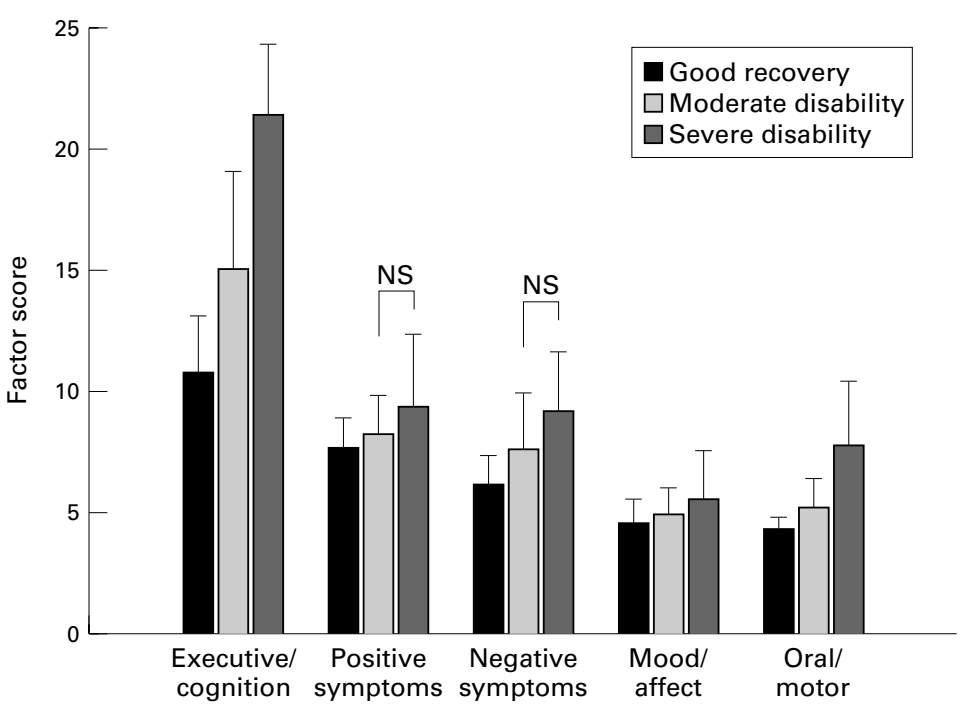

Figure 1 Mean comparisons between groups based on GOS ratings 6 months after injury $(n=210)$. Higher scores indicate greater impairment. All between group comparisons within each factor are significant at $p<0.017$ unless otherwise indicated.
The NRS-R total score correlated significantly with concurrent GOS $(r=0.72)$ and DRS $(r=0.74)$ scores at 6 months. Similar significant correlations were found with each of the five factor scores and the GOS $(r=0.28$ to $0.74)$ and DRS ( $r=0.26$ to 0.74$)$ scores. This suggests that the NRS-R total score is sensitive to global outcome compared with these two widely recognised outcome measures.

\section{VALIDATION WITH NEUROPSYCHOLOGICAL} CONSTRUCTS

The NRS-R factor scores were correlated significantly with specific domains of neuropsychological functioning which included ver$\mathrm{bal}^{35}{ }^{36}$ ) and visual memory, ${ }^{37} 38$ speed dependent visuomotor tracking, ${ }^{25} 3940$ manual dexterity, ${ }^{26}{ }^{27}$ and speeded language production. ${ }^{24}$ Table 4 illustrates the correlations between the NRS-R factor scores and the neuropsychological domain factor scores. The strongest correlations of the mood/affect factor were with neuropsychological domains known to be sensitive to affective disorders (for example, depression) including memory and rapid visual-motor tracking. ${ }^{43-47}$

SENSITIVITY TO CHANGE DURING RECOVERY

To determine the sensitivity of the NRS-R to changes during recovery, the scores of patients who had completed the NRS-R at both the 3 and 6 month assessments $(n=165)$ were compared. The mean difference between the NRS-R total score at 3 and 6 months was significant $(\mathrm{p}<0.0001)$. Additionally, paired $t$ tests 
Table 4 Correlations between neuropsychological domains and NRS-R factor scores at 6 months postinjury

\begin{tabular}{llllllll}
\hline Neuropsychological domains & $n$ & $\begin{array}{l}\text { NRS-R total } \\
\text { score }\end{array}$ & $\begin{array}{l}\text { Executive/ } \\
\text { cognition }\end{array}$ & $\begin{array}{l}\text { Positive } \\
\text { symptoms }\end{array}$ & $\begin{array}{l}\text { Negative } \\
\text { symptoms }\end{array}$ & Mood / affect & Oral/motor \\
\hline Verbal memory & 201 & $-0.51^{\star \star}$ & $-0.58^{\star \star}$ & NS & $-0.24^{\star}$ & $-0.27^{\star \star}$ & $-0.31^{\star \star}$ \\
Visual memory & 192 & $-0.51^{\star \star}$ & $-0.61^{\star \star}$ & NS & NS & $-0.24^{\star}$ & $-0.42^{\star \star}$ \\
Speeded visuomotor & 193 & $-0.61^{\star \star}$ & $-0.70^{\star \star}$ & NS & $-0.30^{\star \star}$ & $-0.30^{\star \star}$ & $-0.46^{\star \star}$ \\
Fine motor dexterity & 191 & $0.46^{\star \star}$ & $0.51^{\star \star}$ & NS & NS & NS & $0.53^{\star \star}$ \\
Speeded verbal production & 199 & $-0.52^{\star \star}$ & $-0.59^{\star \star}$ & NS & NS & NS & $-0.42^{\star \star}$ \\
\hline
\end{tabular}

${ }^{\star} \mathrm{p}<0.001 ;{ }^{\star \star} \mathrm{p}<0.0001$

Verbal memory=Buschke verbal selective reminding test; visual memory=Rey-Osterrieth complex figure (immediate and delay recall); Speeded visuomotor=trail making test $\mathrm{B}$ and symbol digit modalities test (oral and written administrations); fine motor dexterity=grooved pegboard; speeded verbal production=controlled oral word association.

comparing mean differences for each of the five factor scores disclosed significant differences for executive/cognition $(\mathrm{p}<0.0001)$, negative symptoms $\quad(\mathrm{p}<0.006)$, and oral/motor $(\mathrm{p}<0.004)$. Only the positive symptoms and $\mathrm{mood} /$ affect factor scores did not change significantly between 3 and 6 months.

As a more stringent test of the sensitivity of the NRS-R, paired $t$ tests for differences in NRS-R scores were calculated for patients whose GOS score did not change from 3 to 6 months $(n=105)$. Results indicated that the NRS-R total score changed significantly, as well as the executive/cognition and oral/motor factor scores (table 5). In this analysis, the proportion of those whose score changed on the NRS-R total score was $92.3 \%$, whereas $81.9 \%$ changed on the executive/cognition factor score, and $60.0 \%$ changed on the oral $/$ motor factor score. This dissociation implies that although a measure of global outcome (GOS) did not reflect a change in the patient's overall level of recovery, certain factors of the NRS-R were sensitive to changes over time in specific domains of neurobehavioural functioning.

\section{Discussion}

Clinician based instruments allow a trained clinician or psychometrician to make objective assessments of operationally defined classes of behaviour. This makes possible the tracking of behavioural recovery of patients with head injury and allows multiple centres to rate patient behaviour using a standard procedure in multicentre clinical trials. Ambiguity in making NRS-R ratings was reduced by specifically defining each rating level (absent to severe) for each item based on behaviours found during the semistructured interview. However, the clinician is only able to make ratings based on a relatively brief interaction with the patient. For example, the patient may have been hostile to hospital staff or had experienced hallucinations previously in the same day, but if these behaviours were not witnessed at the time of the interview, they would not be recorded in the ratings of the NRS-R. In a clinical setting the NRS-R as a clinician based instrument can be one source of information about a patient's pattern of improvement and residual behavioural deficits when combined with reports from relevant others and the patient's self appraisal. This provides the clinician with a basis from which to determine the accuracy of the patient and family perspective, which can be important for rehabilitation planning.

Instruments used in clinical trials must be able to measure outcome for all or nearly all patients enrolled in order to be viable. Using neuropsychological tests as a primary outcome measure is problematic as many severely impaired patients are not able to comply with all of the tests. In the current study, only $42.5 \%$ of the patients (in the study group) were able to fully complete the 2 hour neuropsychological battery 6 months after injury. In this study, the completion rate for survivors was $97.6 \%$ for the GOS and $96.1 \%$ for the DRS, and the completion rate for the NRS-R was $74.9 \%$. Although neuropsychological data can be very useful in characterising deficits after closed head injury, other measures which require less cooperation from the patient are likely to be more useful in conducting clinical trials. For these reasons, the NRS-R is well suited as a secondary outcome measure in that it quantifies important features of neurobehavioural recovery and places minimal demands on the patient (compared with formal neuropsychological assessment) to carry out basic tasks of reasoning, temporal orientation, memory, language comprehension and expression, and mental calculation. Although certainly not a substitute for a comprehensive neuropsychological evaluation, the NRS-R provides complimentary information about behavioural disturbances which are otherwise difficult to quantify, and which neuropsychological testing alone does not provide.

Table 5 Sensitivity to change for patients whose GOS score remained unchanged from 3 to 6 months $(n=105)$

\begin{tabular}{|c|c|c|c|c|c|c|c|}
\hline & \multicolumn{2}{|c|}{3 Month score } & \multicolumn{2}{|c|}{6 Month score } & \multirow{2}{*}{$\begin{array}{l}\text { Mean } \\
\text { difference* }\end{array}$} & \multirow[b]{2}{*}{$t$ Value } & \multirow[b]{2}{*}{ p Value } \\
\hline & Mean & $(S D)$ & Mean & $(S D)$ & & & \\
\hline NRS-R total score & 43.33 & 10.93 & 42.06 & 9.22 & -1.30 & -1.86 & 0.05 \\
\hline Executive/cognition & 15.5 & 5.42 & 14.83 & 5.14 & -0.67 & -2.34 & 0.02 \\
\hline Positive symptoms & 8.34 & 2.18 & 8.31 & 2.16 & -0.03 & -0.15 & NS \\
\hline Negative symptoms & 5.10 & 1.57 & 4.84 & 1.39 & -0.26 & -1.64 & NS \\
\hline Mood/affect & 7.55 & 2.44 & 7.50 & 2.17 & -0.05 & -0.23 & NS \\
\hline Oral/motor & 5.55 & 1.77 & 5.26 & 1.45 & -0.30 & -2.30 & 0.02 \\
\hline
\end{tabular}

ॠThe mean difference was calculated as the 6 month score minus the 3 month score so that a negative mean difference indicates improvement. 
Interrater reliability for the NRS-R was not consistently high across all items as reported in the study by Vanier et $a l^{18}$ (for example, difficulty in planning). This issue becomes of greater concern as the number of examiners and study centres increases. However, training examiners using videotaped administrations of the NRS-R (initial study training workshops), annual review, observation of testing procedure, and stringent adherence to the scoring guidelines can facilitate maximisation of interrater and test-retest reliability.

At least modest convergent and divergent validity for the factor scores of the NRS-R was shown in that the neuropsychological domain scores were more substantially related to the executive/cognition factor than to other factors. Slightly less robust correlations were also found between the oral/motor factor and the specific neuropsychological domains of speeded visual-motor and manual dexterity abilities as would be expected. Further, the positive symptoms and negative symptoms factors were virtually unrelated to the neuropsychological domains.

Although the NRS-R has a strong factor reflecting executive and general cognitive functioning, this should not be used as a substitute for a detailed cognitive assessment of executive and intellectual functioning. This does not rule out the use of the NRS-R in pharmacological trials-for example, to screen for cognitive declines or improvements as a result of therapeutic agents or other interventions. The NRS-R factor scores could be used as a profile of cognitive, affective, and neuropsychiatric domains demonstrating areas of improvement or decline for specific types of neurobehavioural sequelae. It is possible that this could greatly improve the design of clinical trials which target specific types of outcome and expand the scope of characterising outcome by a global categorisation.

The NRS-R has demonstrated sensitivity to sequelae which contribute to morbidity. Items on the positive symptoms factor are important features of neurobehavioural outcome and have been shown to affect long term outcome after closed head injury. ${ }^{48}$ Additionally, behaviours associated with the negative symptoms and mood/affect factors were only moderately associated with GOS and DRS scores, but have long term implications for rehabilitation and community re-entry. ${ }^{50} 51$

There are striking differences between the factor solution for the NRS reported by Levin et $a l^{1}$ and the current NRS-R. One possibility is the larger sample size of the current study. However, several other plausible reasons exist. Firstly, the NRS was validated on a heterogeneous group of patients with closed head injury encompassing the full range of injury severity and widely variable degrees of chronicity. Conversely, the current NRS-R study was based on a fairly homogenous sample of patients with severe closed head injury and tightly defined end points of 3 and 6 months after injury. Another possibility is the change in the Likert scale used to rate each item; the NRS-R has four rating levels ranging from absent to severe instead of the more complicated seven point scale of the NRS. Based on previous experience with the NRS and recovery from head injury, two new items were added: "irritability" and "difficulties in mental flexibility". Both items represent important aspects of neurobehavioural outcome. Mental inflexibility is considered a hallmark symptom of frontal lobe dysfunction and has been hypothesised to be a potential obstacle to resuming adequate social functioning and employment. ${ }^{51-57}$ Similarly, irritability has often been documented in studies based on reports by relatives of patients recovering from severe closed head injury. ${ }^{58}$ Combining the items "tension" and "anxiety" to form "anxiety" seems to be an improvement given the ambiguity of the tension item and the weak loading it had on the somatic/anxiety factor of the NRS. The division of the "inattention" item into separate components of "reduced alertness" and "attention" may have had an effect on the factor structure of the current solution by distinguishing impaired alertness or general arousal from focused concentration on a task. Both features are important considerations, but "reduced alertness" is likely to be more meaningful at early stages of recovery whereas "attention" may have greater implications in the postacute phase.

Two minor differences were noted between the results of the current factor analysis and those reported by Vanier et al. ${ }^{18}$ These differences likely stem from two principal sources. The first is that, as in the study by Levin et al, ${ }^{1}$ the full range of head injury severity was included in the. investigation of Vanier et al as opposed to a homogeneous sample of severe head injuries in the current study. Secondly, both the original study of Levin et al and that of Vanier et al had wide ranging time points after injury when assessments occurred. In the current study, all patients were tested within relatively narrow windows at about 3 and 6 months after injury. Despite the differences in severity of closed head injury and follow up intervals after injury, the factor solutions found in this multicentre clinical trial and those reported by Vanier et al are quite similar. For instance, the executive/cognition factor has seven out of eight of the items loading on the intentional behaviour factor of Vanier et al. The positive symptoms factor is identical to that of Vanier et al except for the inclusion of "irritability". The current results generally seem to confirm the factor solution reported by Vanier et al.

Given the differences between the factor structure in this study and the one reported by Vanier et al, we suggest using the following guidelines for the appropriate use of the NRS-R factor scores, as both solutions are useful. Studies investigating the full range of head injury severity and heterogeneous chronicity would be advised to use the factor solution reported by Vanier et al. ${ }^{18}$ Studies of a homogeneous group of severe head injuries using about 6 months as a consistent end point should consider using the factor structure reported in this study. 
The factor structure reported here fits well with the known major cognitive, emotional and behavioural sequelae of severe closed head injury, and Luria's three units model of functional organisation of the brain ${ }^{5960}$ as described by Vanier et al. ${ }^{18}$ The executive/ cognition factor encompasses important areas of cognition often impaired in closed head injury (memory and temporal orientation) as well as major elements of executive dysfunction (planning, mental flexibility, self appraisal, conceptual disorganisation, and initiative or motivation) which have been shown to contribute significantly to long term disability ${ }^{53-57}$ and failure to return to work, ${ }^{54}$ and to impose serious emotional burden on family members. ${ }^{61-64}$ The positive symptoms factor includes items which are important not only in the acute phase, but have been shown to persist up to 10 or 15 years after njury. ${ }^{6165-68}$ the negative symptoms factor reflects reduced initiation and lack of emotional variation occasionally seen in damage to the frontal lobes. The mood/affect factor could be useful in tracking emotional reactions as a patient's level of self awareness increases or in studying closed head injury related mood disorders. As demonstrated by the factor's correlation with neuropsychological domains, the oral/motor factor taps both verbal output as well as deficits in psychomotor speed and dexterity which are commonly seen in severe closed head injury. ${ }^{69} 70$

This study was supported by grants NS-32786 and 21889 from the National Institutes of Health and CDC 49CCR612707-01 from the Centers for Disease Control and Prevention.

1 Levin HS, High WM, Goethe KE, et al. The neurobehavioural rating scale: assessment of the behavioural sequelae of head injury by the clinician. 7 Neurol Neurosurg Psychiatry 1987;50:183-93.

2 Overall JE, Gorham DR. The brief psychiatric rating scale. Psychol Rep 1962;10:799-812.

3 Corrigan JD, Dickerson J, Fisher E, et al. The neurobehavioural rating scale: replication in an acute, inpatient roural rating scale: replication in an acute, inp

4 Sultzer DL, Berisford MA, Gunay I. The neurobehavioral rating scale: reliability in patients with dementia. F Psychiatr rating scale: reliability

5 Hilton G, Sisson R, Freeman E. The neurobehavioral rating scale: an interrater reliability study in the HIV seropositive population. $\mathcal{F}$ Neurosci Nurs 1990;22:36-42.

6 Dombovy ML, Olek AC. Recovery and rehabilitation following traumatic brain injury. Brain Injury 1997;11:30518.

7 Cifu DX, Keyser-Marcus L, Lopez E, et al. Acute predictors of successful return to work 1 year after traumatic brain injury: a multicenter analysis. Arch Phys Med Rehabil 1997; 78: $125-31$.

8 Gualtieri CT. Buspirone for the behavior problems of patients with organic brain disorders. F Clin Psychopharmacol 1991;11:280-1.

9 Vilkki J, Ahola K, Holst P, et al. Prediction of psychosocial recovery after head injury with cognitive tests and neurobehavioral ratings. F Clin Exp Neuropsychol 1994;16:325-38.

10 Mazaux, J-M, Masson F, Levin HS, et al. Long-term neuropsychological outcome and loss of social autonomy after traumatic brain injury. Arch Phys Med Rehabil 1997;78: 1316-20

11 Sultzer DL, Levin HS, Mahler ME, et al. Assessment of cognitive, psychiatric, and behavioral disturbances in patients with dementia: the neurobehavioral rating scale. $f$ Am Geriatr Soc 1992;40:549-55.

12 Sultzer DL, Mahler ME, Mandelkern MA, et al. The relationship between psychiatric symptoms and regional cortical metabolism in Alzheimer's disease. $\mathcal{F}$ Neuropsychiatry Clin Neurosci 1995;7:476-84.

13 Sultzer DL, Mahler ME, Cummings JL, et al. Cortical abnormalities associated with subcortical lesions in vascular dementia: clinical and position emission tomographic findings. Arch Neurol 1995;52:773-80.

14 Sultzer DL, Levin HS, Mahler ME, et al. A comparison of psychiatric symptoms in vascular dementia and hiatry 1993;150:1806-12.

15 Mulsant BH. Methodological issues in characterizing treatment response in demented patients with behavioral disturbances. Int f Geriatr Psychiatry 1997;12:537-47.
16 Foglia JP. Plasma levels of citalopram enantiomers and metabolites in elderly patients. Psychopharmacol Bull 1997; 33:109-12

17 Levin HS, Mazaux J-M, Vanier M, et al. Evaluation des troubles neurophysiologiques et comportementaux des traumatisés crâniens par le clinicien: proposition d'une échelle neurocomportementale et premiers résultats de sa version française. Annales de Réadaptation et de Médecine Physique 1990;33:35-40.

18 Vanier M, Mazaux J-M, Lambert J, et al. Assessment of neuropsychologic impairments after head injury: interrater reliability and factorial and criterion validity of the neurobehavioral rating scale, revised. Arch Phys Med Rehabil 2000;81:796-806

19 Teasdale G, Jennett B. Assessment of coma and impaired consciousness: a practical scale. Lancet 1974;ii:81-4.

20 Association for the Advancement of Automotive Medicine. Abbreviated injury scale, 1990 revision. Des Plaines, IL: AAAM, 1990

1 Bennett B, Bond M. Assessment of outcome after severe brain damage. Lancet 1975; i:480-84.

22 Bennett B, Snoek J, Bond MR, et al. Disability after severe head injury: observations on the use of the Glasgow outcome scale. F Neurol Neurosurg Psychiatry 1981;44:285-93.

23 Rappaport M, Hall K, Hopkins K, et al. Disability rating scale for severe head trauma: coma to community. Arch scale for severe head trauma: com
Phys Med Rehabil 1982;63:118-23.

24 Benton A, Hamscher K. Multilingual aphasia examination. 2nd ed. Iowa: University of Iowa, 1989.

25 Army individual test battery. Manual of directions and scoring. Washington, DC: War Department, Adjutant General's Office, 1944.

26 Kløve H. Clinical neuropsychology. In: Forster FM, ed. The medical clinics of North America. New York: Saunders, 1973.

27 Matthews CG, Kløve H. Instruction manual for the adult neuropsychology test battery. Madison, Wisconsin: The University of Wisconsin Medical School, 1974

28 Karlsson C, Von Essen C, Lofgren J. Factors affecting the clinical course of patients with severe head injuries. $\mathcal{F} \mathrm{Neu}$ rosurg 1968;29:242-51.

29 Heiskanen O, Sipponen P. Prognosis of severe brain injury. Acta Neurol Scand 1970;46:343-8.

30 Jane JA, Francel PC. Age and outcome of head injury. In: RK Narayan, JE Wilberger, JT Povlishock, eds. Neurotrauma. New York: McGraw-Hill, 1996:793-804.

31 Bennett B, Teasdale G, Braakman R, et al. Predicting outcome in individual patients after severe head injury. Lancet 1976;i:1031-4

32 Bennett B, Teasdale G, Braakman R, et al. Prognosis of patients with severe head injury. Neurosurgery 1979;4:283-9.

33 Russell WR, Smith A. Post-traumatic amnesia in closed head injury. Arch Neurol 1961;5:16-29.

34 Clifton GL, Hayes RL, Levin HS, et al. Outcome measures for clinical trials involving traumatically brain-injured patients: report of a conference. Neurosurgery 1992;31:975-

35 Buschke H, Fuld PA. Evaluation of storage, retention, and retrieval in disordered memory and learning. Neurology 1974;11:1019-25.

36 Larrabee GJ, Trahan DE, Curtiss G, et al. Normative data for the verbal selective reminding test. Neuropsychology 1988;2:173-82.

37 Rey A. L'examen psychologique dans les cas d'encéphalopathie traumatique. Archives de Psychologie 1941;28:286-340

38 Osterrieth PA. Le test de copie d'une figure complexe. Archives de Psychologie 1944;30:206-356.

39 Smith A. The symbol-digit modalities test: a neuropsychologic test for economic screening of learning and other cerlogic test for economic screening of learning and

40 Smith A. Symbol-digit modalities test (SDMT) manual (revised). Los Angeles; Western Psychological Services, 1982

41 Tabachnick BG, Fidell LS. Using multivariate statistics. 2nd ed. New York: Harper Collins, 1989.

42 Stevens J. Applied multivariate statistics for the social sciences. Mahwah, NJ: Lawrence Erlbaum Associates, 1996.

43 Hart RP, Kwentus JA, Taylor JR, et al. Rate of forgetting in dementia and depression. $\mathcal{F}$ Consult Clin Psychol 1986;55: $101-5$.

44 Weingartner $\mathrm{H}$. Automatic and effort-demanding cognitive processes in depression. In: Poon LW, ed. Handbook of clinical memory assessment in older adults. Washington, DC: American Psychological Association, 1986:218-27.

45 Kaszniak AW, Poon LW, Riege W. Assessing memory deficits: an information processing approach. In: Poon LW, deficits: an information processing approach. In: Poon LW, ed. Handbook of clinical memory assessment in older adults. Washington, D

46 Gass CS, Daniel SK. Emotional impact on trail making test performance. Psychol Rep 1990;67:435-8.

7 King DA, Caine ED. Depression. In: Cummings JL, ed. Subcortical dementia. New York: Oxford University Press, 1990:218-30.

48 Silver JM, Yudofsky SC. Aggressive disorders. In: Silver JM, Yudofsky SC, Hales RE, eds. Neuropsychiatry of traumatic brain injury. Washington, DC: American Psychiatric Press, 1994:313-56.

49 Kant R, Duffy JD, Pivovarnik A. Prevalence of apathy following head injury. Brain Inj 1998;12:87-92.

50 Federoff PJ, Starkstein SE, Forrester AW, et al. Depression in patients with acute traumatic brain injury. Am F Psychiatry 1992;149:918-23. 
51 Jorge RE, Robinson RG, Arndt SV, et al. Comparison between acute- and delayed-onset depression following traumatic brain injury. $\mathcal{f}$ Neuropsychiatry Clin Neurosci 1993;5:43-9.

52 Bayless JD, Varney NR, Roberts RJ. Tinker toy test performance and vocational outcome in patients with closed-head injuries. F Clin Exp Neuropsychol 1989;11:91317.

53 Ben-Yishay Y, Silver SM, Piasetsky E, et al. Relationship between employability and vocational outcome after intensive holistic cognitive rehabilitation. F Head Trauma Rehabi 1987;2:35-48.

54 Fraser R, Dikmen S, McLean A, et al. Employability of head injury survivors: first year post-injury. Rehabilitation Counseling Bulletin 1988;31:276-88.

55 Girard D, Brown J, Burnett-Stolnack M, et al. The relationship of neuropsychological status and productive outcomes following traumatic brain injury. Brain Injury 1996;10:663follow

56 Kay T, Silver SM. The contribution of neuropsychological Kay T, Silver SM. The contribution of neuropsychological evaluation to the vocational rehabilitation of the
injured adult. F Head Trauma Rehabil 1988;3:65-76.

57 Varney NR, Menefee MS. Psychosocial and executive defiarney NR, Menefee MS. Psychosocial and executive defi-
cits following closed-head injury: implications for orbital cits following closed-head injury: implications for orbit

58 McKinlay WW, Brooks W. Personality and behavioral change after severe blunt head injury: a relative's view. $\mathscr{f}$ Neurol Neurosurg Psychiatry 1983;46:336-44

59 Luria AR. Higher cortical functions in man. NY: Basic Books, 1966.
60 Luria AR. The working brain. Penguin Books, 1973.

61 Thomsen IV Late outcome of very severe blunt head trauma: a 10-15 year second follow-up. 7 Neurol Neurosurg Psychiatry 1984; 47:260-8.

62 Brooks DN, Campsie L, Symington C, et al. The 5 year outcome of severe blunt head injury: a relative's view. $\mathcal{F}$ Neurol Neurosurg Psychiatry 1986;49:764-70.

63 Oddy M, Coughlan T, Tyerman A, et al. Social adjustment after closed-head injury: a further follow up 7 years after injury. F Neurol Neurosurg Psychiatry 1985;48:564-8.

64 Thomsen IV. Late psychosocial outcome in severe traumatic brain injury. Scand $\mathcal{F}$ Rehabil Med 1992;26(suppl):142-52.

65 Achte K, Jarho L, Kyykka T, et al. Paranoid disorders following war brain damage: preliminary report. Psychopathology 1991;24:309-15.

66 Hillbom E. Schizophrenia-like psychoses after brain trauma. Acta Psychiatr Scand 1951;60(suppl):36-47.

67 Smeltzer DJ, Nasrallah HA, Miller SC. Psychotic disorders. In: Silver JM, Yudofsky SC, Hales RE, eds. Neuropsychiatry
Int of traumatic brain injury. Washington, DC: American of traumatic brain injury. Washic

68 Violon A, De Mol J. Psychological sequelae after head trauma in adults. Acta Neurochirgica (Wien) 1987;85:96-

69 Clifton GL, Kreutzer JS, Choi SC, et al. Relationship between Glasgow outcome scale and neuropsychological measures after brain injury. Neurosurgery 1993;33:34-9.

70 Tabaddor K, Mattis S, Zazula T. Cognitive sequelae and recovery course after moderate and severe head injury. Neurosurgery 1984;14:701-08.

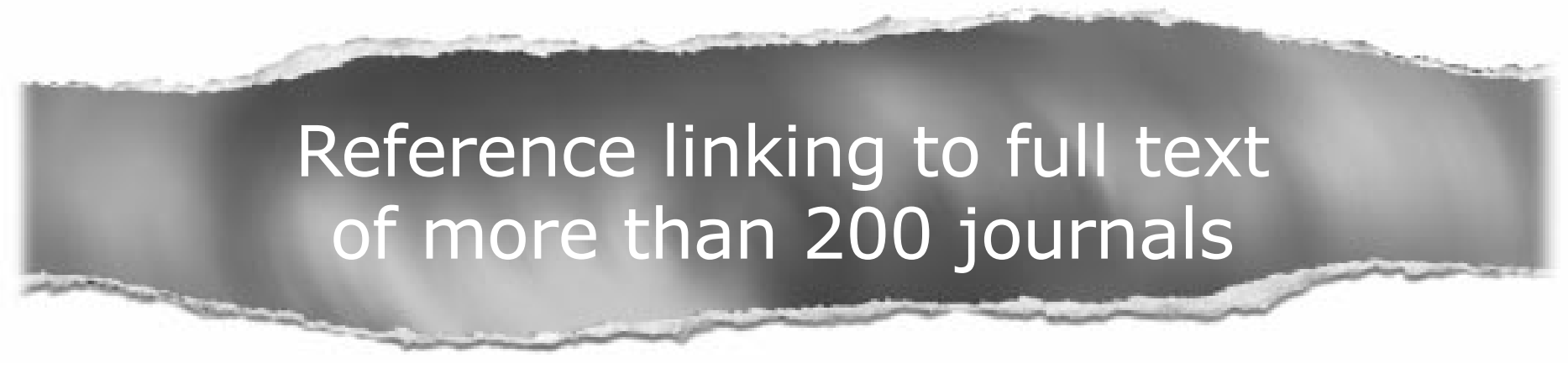

\section{Toll free links}

You can access the FULL TEXT of articles cited in the Journal of Neurology, Neurosurgery, and Psychiatry online if the citation is to one of the more than 200 journals hosted by HighWire (http://highwire.stanford.edu) without a subscription to that journal.

There are also direct links from references to the Medline abstract for other titles.

www.jnnp.com 